\title{
Ultra-High-Speed Magnetic Abrasive Surface Micro-Machining of AISI 304 Cylindrical Bar
}

\author{
Cheng Yin ${ }^{1}{ }^{\oplus}$, Rui Wang ${ }^{2}{ }^{\circledR}$, Jeong Su Kim ${ }^{1}$, Sang Wan Lee ${ }^{1}$ and Sang Don Mun ${ }^{1, *}$ \\ 1 Division of Mechanical Design Engineering, Chonbuk National University, 664-14, Duckjin-gu, \\ Jeonju 761-756, Korea; yoonsung_ys@hotmail.com (C.Y.); jeongsu1592@naver.com (J.S.K.); \\ cobacoba00@naver.com (S.W.L.) \\ 2 Division of Mechanical Design Manufacturing and Automation, Shijiazhuang Rail University, \\ Shijiazhuang 050043, China; wangruiaa@hotmail.com \\ * Correspondence: msd@jbnu.ac.kr; Tel.: +82-63-270-4762
}

Received: 4 February 2019; Accepted: 24 April 2019; Published: 27 April 2019

check for updates

\begin{abstract}
The ultra-high-speed magnetic abrasive machining (UHSMAM) process is a surface improvement technique, which has been widely used to minimize the surface accuracy and change the precision morphology of difficult-to-machine materials. Surface integrity plays an important role in the machining process, because it is used to evaluate the high stress and the loaded components on the machined surface. It is important to evaluate the plastically deformed layers in ultra-precision machining surface of material. However, the usual plastic strains in the ultra-precision machining surface are significantly difficult to consider. In this paper, an ultra-high-speed magnetic abrasive machining technique is used to improve the surface accuracy and dimensional accuracy of an AISI 304 bars. Additionally, the subsequent recrystallizations technique is used for measuring the plastic strain on machined surface of AISI 304 bars. The purpose of this paper is to evaluate the effects of an UHSMAM process on the plastic strains and the strain energy of the machined surface, and to evaluate the residual strain in the plastic deformation of AISI 304 bars materials by analyzing a plastically deformed layer. The results showed that the plastic strain of the material did not change after machined by an UHSMAM process. Based on the results, an UHSMAM process could significantly improve the surface roughness, micro-diameter, and removal weight of AISI 304 bars effectively. The surface roughness Ra of AISI 304 bars was improved from $0.32 \mu \mathrm{m}$ to $0.03 \mu \mathrm{m}$ for $40 \mathrm{~s}$ of machining time at $80,000 \mathrm{rpm}$ of workpiece revolution speed.
\end{abstract}

Keywords: ultra-high-speed magnetic abrasive machining; surface accuracy; dimensional accuracy; recrystallization technique; surface integrity; plastic strain

\section{Introduction}

Ultra-high-speed magnetic abrasive machining process is an advanced machining technique, which has been used to improve the surface accuracy and dimensional accuracy of difficult-to-machine materials in the manufacturing industries. In previous work, some conventional processing methods (i.e., honing, lapping, polishing, grinding, and super finishing) are used to improve the high surface quality of the produces produced by the manufacturing process [1-3]. Kuhar et al. [4] used the polishing method to improve the surface roughness of an acrylic. He reported that the polishing method could produce the smoothest surface for an acrylic denture workpiece. Mahajan et al. [5] reported that the burnishing method can be used to improve the workpiece surface by using the hardened steel ball to press on the workpiece surface. The burnishing method has provided good results in the surface roughness of cylinder holes and tubes. 
Despite the potential advantages of these processes, there are numerous limitations on the surface finish of difficult-to-machine materials, 3-D complex shape materials, and processing time [6,7]. These limitations involve the high-cost requirement to accurately improve the surface of difficult-to-machine materials, high-energy consumption, and lower eco-friendly safety. Furthermore, these surface processing methods use high pressure on the material surface during their processing. Therefore, the surface that needs to be finished can be damaged by their high pressure. Park et al. [8] reported that some surface processing methods (i.e., lapping, grinding, and honing) are inappropriate to process parts with micro-scale shapes, small-scale sizes, and three dimensional shapes of the workpiece material. Singh et al. [9] reported that some conventional grinding or finishing techniques are not suitable to process advanced materials with stringent mechanical properties (i.e., zirconia ceramic $\mathrm{ZrO}_{2}$, silicon nitride $\mathrm{Si}_{3} \mathrm{~N}_{4}$, and silicon carbide $\mathrm{SiC}$ ) to achieve high surface accuracy or dimensional accuracy with minimal surface defects. Therefore, in order to overcome these limitations, many researchers have tried to adopt new different advanced surface improvement methods to replace these conventional methods [10]. Wojciechowski et al. [11] reported that a precise machining method is a new advanced technology that is able to achieve a very high machined surface texture of the geometrical product specification (GPS). Heng et al. [6] developed a novel ultra-high-precision magnetic abrasive finishing for improving the surface accuracy of AISI 1085 steel wire material. He concluded that a novel finishing method can improve the original surface roughness $R$ a from $0.25 \mu \mathrm{m}$ to $0.02 \mu \mathrm{m}$ for $60 \mathrm{~s}$. Sun et al. [12] improved the surface accuracy of stainless steel SUS 304 plane using the electrolytic magnetic abrasive finishing process. He concluded that the surface roughness Ra of SUS304 plane can be improved to $0.03 \mu \mathrm{m}$ for $4 \mathrm{~min}$ using an electrolytic magnetic abrasive finishing process. The ultra-high-speed magnetic abrasive machining process is one of the new advanced surface improvement techniques, which can be used to improve the surface accuracy and dimensional accuracy of difficult-to-machine material. In this work, the machining equipment using an UHSMAM technique is used with the purpose to improve the finishing accuracy of AISI 304 material in terms of the surface roughness $\mathrm{Ra}$, micro-diameter, and removal weight of material. The UHSMAM technique is well known due to its potential advantages (i.e., short machining time and high machining capability). The material properties of machine components (i.e., fatigue strength, ultimate tensile strength, and stress corrosion cracking) can be affected by damaged layer or the plastically deformed layer on the machined surface after the machining or cutting method [13]. Hence, these material properties have been called the surface integrity. Therefore, after the ultra-high-speed machining process, the effect of damaged layer or the plastically deformed layer on the machined precision surface must be considered [14].

However, it is very difficult to measure the plastically deformed layer on a machined surface material by the conventional measurement methods, because the deformed region is located in within extremely short distance from the workpiece surface. In previous works, some conventional methods (i.e., metallographic etching, dislocations structure method, and grid method) were used to measure the plastically deformed layer. However, currently it is impossible to use these methods. In this study, the subsequent recrystallizations technique is used to measure the plastic strain on the machined surface of AISI 304 bar after being machined by an ultra-high-speed magnetic abrasive machining process. The AISI 304 bar is one of the useful materials that are widely used in medical devices, nuclear industries, and medical enterprise. This material was selected as the cylindrical workpiece and machined by an ultra-high-speed magnetic abrasive machining process with the optimal input parameters.

In this study, a difficult-to-machine AISI 304 bar material that was ground by a flexible magnetic abrasive brush was machined via an ultra-high-speed magnetic abrasive machining process with the different parameters (i.e., 80,000 rpm of workpiece rotational speed, $550 \mathrm{mT}$ of magnetic flux density, $10 \mathrm{~Hz}$ of vibration frequency, and $0.5 \mu \mathrm{m}$ of diamond abrasive particles). The evaluation of the ultra-precision machining surface with the plastic strain of AISI 304 bar was carried out and then the surface roughness, micro-diameter, and removal weight were analyzed. 


\section{Experimental Method}

\subsection{UHSMAM Process for AISI 304 Bars}

Figure 1 shows a schematic of an ultra-high-speed magnetic abrasive machining principle for AISI 304 cylindrical bar. The unbonded magnetic abrasive tools are inserted inside the gap of the south-pole and the north-pole of Nd-Fe-B permanent magnets; the mixture of magnetic abrasive tools forms a flexible magnetic abrasive brush along the lines of magnetic force. A cylindrical AISI 304 bar is inserted inside the flexible magnetic abrasive brush and then rotated at an ultra-high-speed (80,000 rpm). The vibration action $(10 \mathrm{~Hz})$ of magnetic poles is applied in the longitudinal direction. The processing magnetic force comprises a force $\left(F_{x}\right)$ in the direction of the magnetic force line. The force $\left(F_{x}\right)$ strongly acts on the magnetic particles, against which the surface of AISI 304 bar workpiece lies along the magnetic force lines. A force $\left(F_{y}\right)$ is generated when the AISI 304 bar workpiece pushes out the bridges formed in the direction of magnetic equipotential lines. Here, a yoke is specially designed according to the magnetic field effect; it is made by SS 41 steel and gathers the magnetic field. The magnetic forces $\left(F_{x}\right)$ and $\left(F_{y}\right)$ act on the surface of AISI 304 bar workpiece, which results in a grinding effect. Here, the magnetic abrasive particle brushes have many degrees of freedom, and become flexible enough to accommodate the surface conditions of the workpiece. Figure 2 shows a schematic view of normal force $\left(F_{\mathrm{N}}\right)$ and tangential force $\left(F_{\mathrm{T}}\right)$ of magnetic force acting on abrasive particle during the machining process.

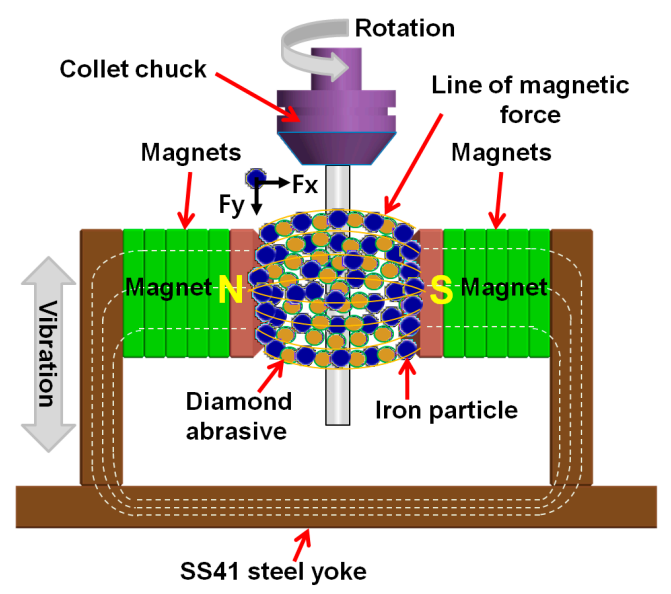

Figure 1. Schematic of ultra-high-speed micro magnetic abrasive machining principle.

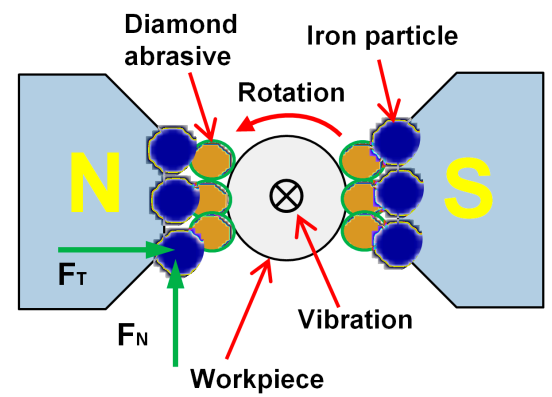

Figure 2. Schematic view of normal force $\left(F_{\mathrm{N}}\right)$ and tangential force $\left(F_{\mathrm{T}}\right)$ of magnetic force acting on abrasive tool.

Figure 3 shows the photo of an ultra-high-speed magnetic abrasive machining apparatus for AISI 304 cylindrical bars. This apparatus is composed of an ultra-high-speed spindle, a SS 41 steel yoke, a cylindrical workpiece, several Nd-Fe-B permanent magnets, and an electromotive slider. The austenitic stainless steel bars (AISI 304 bar, dimensions: $\varnothing 3 \times 50 \mathrm{~mm}^{2}$; Ra: $0.32 \mu \mathrm{m}$ ) were used as the cylindrical workpieces for this experimental work. The cylindrical workpiece was inserted inside 
the collet chuck of an ultra-high-speed air spindle (speed range: 1000-80,000 rpm), and the unbonded magnetic abrasive tools were inserted into the machined area [15]. The cylindrical workpiece was rotated at an ultra-high-speed $(80,000 \mathrm{rpm})$, and the electromotive liner slider was used to generate the vibration action of the magnetic poles at $10 \mathrm{~Hz}$ of vibration frequency with $2 \mathrm{~mm}$ of amplitude.

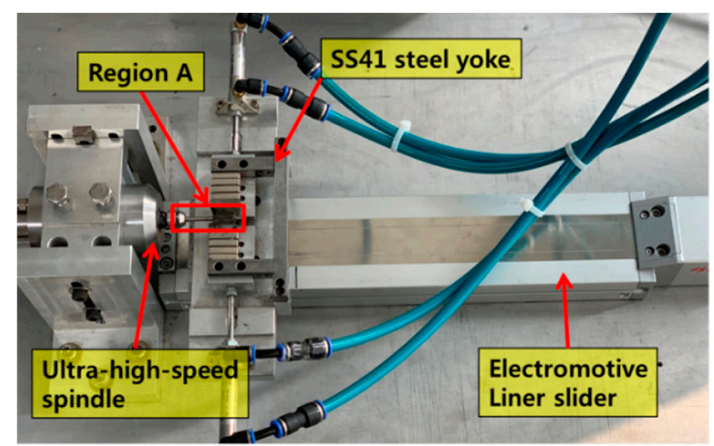

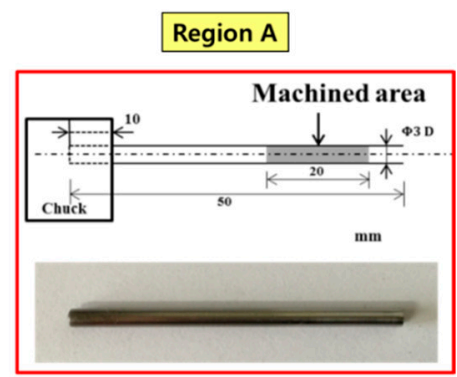

(a) Processing unit

Figure 3. Photo of ultra-high-speed magnetic abrasive machining (UHSMAM) process apparatus with cylindrical workpiece.

\subsection{Surface Integrity for Machining Surface by Subsequent Recrystallizations Technique}

In this work, the subsequent recrystallization method was used to measure the plastic strain on the surface of workpiece before and after the machining process using the recrystallization phenomena. Figure 4 shows the machined surface area of the AISI 304 cylindrical bars. In order to prevent the machined surface from the plastic deformation, the machined surface area of AISI 304 bar workpiece was cut off by the wire electrical discharge machine EDM. The cutting cylindrical workpiece was used for anneal (recrystallization temperature at $950{ }^{\circ} \mathrm{C}$ for $24 \mathrm{~h}$ ), mechanically polished, and then etched in a chemical etchant $\left(\mathrm{C}_{2} \mathrm{H}_{5} \mathrm{OH}: \mathrm{HCl}: \mathrm{HNO}_{3}=100: 15: 30\right)$ to observe the recrystallized zone.

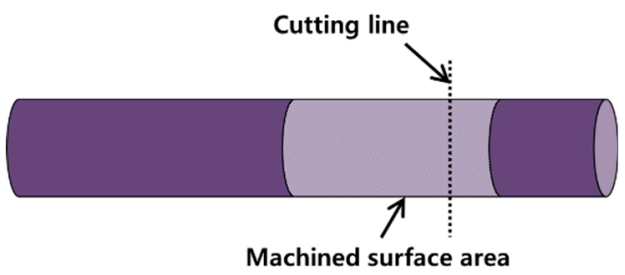

Figure 4. Cutting area of cylindrical workpiece.

The fatigue cracks usually nucleate on the workpiece surface after the machining process. Thus, the surface condition plays an important role in the fatigue resistance of a component. Therefore, the fatigue strength often varies greatly depending on the surface condition of the material. The fatigue failure of material starts from the deteriorated surface roughness of material. Therefore, UHSMAM process is required for improving the surface roughness of material and tensile strength. Figure 5 shows the effects of the surface finish on fatigue endurance limit [16]. In previous work, many researchers have studied the surface finish effects on fatigue endurance limit. It can be confirmed that the polishing process is the best method, which is suitable to enhance the fatigue limit of the materials but only emphasizes the traditional mirror polishing processing. In this study, UHSMAM process was applied for machining the surface of AISI 304 bar material and to study the effect of this method on the enhancement of surface roughness and the tensile strength of materials with a short processing time and then assesses the machining capabilities for application to improve the life of materials. 


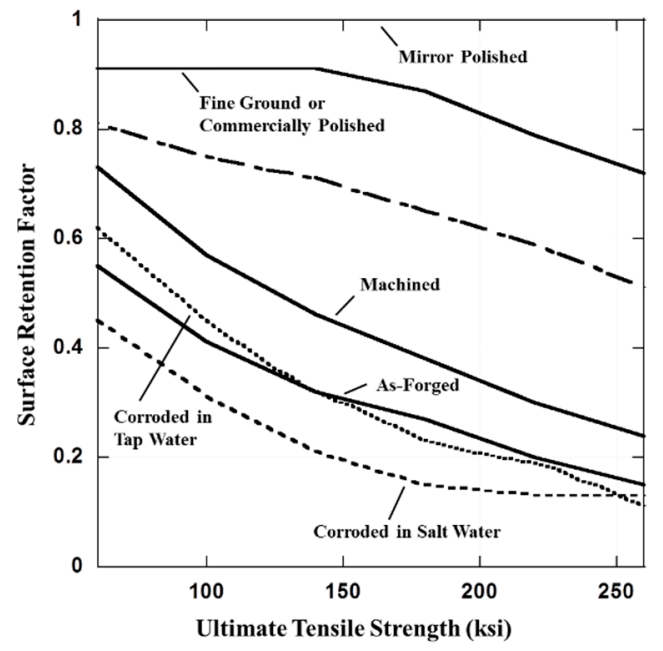

Figure 5. Surface finish effects on fatigue endurance limit [16].

\section{Experimentation Details of UHSMAM Process}

Table 1 shows the experimentation details of an UHSMAM process. As mentioned above, the AISI $304 \mathrm{bar}$ ( $3 \mathrm{~mm}$ in diameter and $50 \mathrm{~mm}$ in length) was used as the cylindrical workpiece and rotated at $80,000 \mathrm{rpm}$ of workpiece rotational speed. Two sets of Nd-Fe-B permanent magnets were applied for producing the magnetic flux density (MFD) up to $550 \mathrm{mT}$. The vibration action of the magnetic poles was $10 \mathrm{~Hz}$ with $2 \mathrm{~mm}$ of the amplitude. Table 2 shows the mechanical and physical properties of AISI 304 cylindrical bar.

Table 1. Experimental conditions.

\begin{tabular}{cc}
\hline Workpiece & AISI 304 bar $\left(\varnothing 3 \times 50 \mathrm{~mm}^{2}\right)$ \\
\hline Workpiece revolution & $80,000 \mathrm{rpm}$ \\
\hline Workpiece pole tip clearance & $1 \mathrm{~mm}$ \\
\hline Lubricant & Light oil, $0.1 \mathrm{~mL}$ \\
\hline Magnetic tool & $\begin{array}{c}\text { Iron particles: } 200 \mu \mathrm{m}, 70 \mathrm{mg} \\
\text { Diamond paste: } 0.5 \mu \mathrm{m}, 10 \mathrm{mg}\end{array}$ \\
\hline Magnetic flux density & $550 \mathrm{mT}$ \\
\hline Vibration of magnetic pole & $10 \mathrm{~Hz}$ \\
\hline Amplitude & $2 \mathrm{~mm}$ \\
\hline Machining time & $0-120 \mathrm{~s}$ \\
\hline
\end{tabular}

Table 2. Mechanical and physical properties of AISI 304 cylindrical bar.

\begin{tabular}{cc}
\hline Young modulus & $201 \mathrm{GPa}$ \\
\hline Poisson ratio & 0.3 \\
\hline Yield strength & At $30{ }^{\circ} \mathrm{C}, 205 \mathrm{GPa}$ \\
\hline Ultimate tensile strength & $515 \mathrm{MPa}$ \\
\hline Allowable stress & At $30{ }^{\circ} \mathrm{C}, 183 \mathrm{MPa}$ \\
\hline Thermal expansion coefficient & $1.33 \times 10^{-5}$ \\
\hline Thermal conductivity & $14.8 \mathrm{~W} / \mathrm{mk}$ \\
\hline Specific heat & $480 \mathrm{~J} / \mathrm{kg} \cdot \mathrm{K}$ \\
\hline Mass density & $7900 \mathrm{Kg} / \mathrm{m}^{3}$ \\
\hline
\end{tabular}




\section{Experimental Results}

Figures 6 and 7 show the largely linear relationship between the change of diameter and material removal against the machining time, respectively. AISI 304 bar workpieces were rotated at 80,000 rpm, and the magnetic poles were vibrated at $10 \mathrm{~Hz}$. As shown in Figure 6, the slope of change of diameter and material removal linearly increased from 0 to $120 \mathrm{~s}$ of the machining time. In terms of the change of diameter, the UHSMAM process can remove 5- $\mu \mathrm{m}$ from diameter of a cylindrical workpiece with every $20 \mathrm{~s}$ (see Figure 7), which the current processing methods are impossible. The slope of material removal shows the constant removal pattern based on the usage of the same grain size of diamond abrasive particle $(0.5 \mu \mathrm{m})$. Figure 8 shows the relationship between the surface roughness (arithmetical average surface roughness, $\mathrm{Ra}$ ) and the machining time. The cylindrical workpiece was rotated at $80,000 \mathrm{rpm}$, and the magnetic poles were vibrated at $10 \mathrm{~Hz}$. Based on the results, the surface roughness Ra was immediately improved from the initial machining time at $0 \mathrm{~s}$ to the machining time at $20 \mathrm{~s}$. The initial surface roughness Ra was improved from 0.32 to $0.04 \mu \mathrm{m}$ for $20 \mathrm{~s}$. After $40 \mathrm{~s}$, the initial surface roughness was improved to $0.03 \mu \mathrm{m}$. According to the results, the ultra-high-speed magnetic abrasive machining processing required $40 \mathrm{~s}$ to achieve the most perfect state of surface roughness (Ra) of cylindrical workpiece such as AISI 304 bar. However, the surface roughness Ra of AISI 304 bar does not improve further after $40 \mathrm{~s}$, because the UHSMAM process can effectively remove only the uneven surface. Figure 9 shows the atomic force microscope (AFM) micro images of cylindrical workpiece's surfaces before and after the machining process by an ultra-high-speed magnetic abrasive machining process at $80,000 \mathrm{rpm}$. As shown in Figure 9a, before the machining process, the deep grooves and the unevenness are found throughout the surface of the AISI 304 bar. Figure $9 \mathrm{~b}$ shows the atomic force microscope (AFM) image of a cylindrical workpiece's surfaces after the machining process by an UHSMAM process at $80,000 \mathrm{rpm}$ for $40 \mathrm{~s}$ of machining time. According to the result, the surface roughness Ra was improved to $0.03 \mu \mathrm{m}$. As shown in the Figure $9 \mathrm{~b}$, the deep grooves and the unevenness were mostly removed from the machined surface of AISI 304 bar. Figure 10 shows the annealed microstructure on the cutting surface of the AISI 304 bar workpiece after machining by an UHSMAM process. In this process, the plastic deformed zones on the surface workpiece at the machining tip increase with the machining depth of workpiece. After the annealing, the recrystallized grain size in the primary deformation zone is found to be smaller than the surrounding region. Regarding the obtained results, it can be confirmed that the primary deformation zone is deformed. The micrographs are shown in Figure 10b; the strain distribution around the machining surface cannot be drawn before the machining process. As shown in Figure 10a,b before and after the machining process, each crystal particle is approximately $350 \mu \mathrm{m}$, and the isotropic shape of microstructure have not changed. Thus, it can be confirmed that an ultra-high-speed magnetic abrasive machining technique did not affect the plastically deformed machined surface.

The surface modification factor can be expressed by Equation (1), as follows:

$$
K_{s}=a S_{u}^{b}
$$

where $K_{\mathrm{S}}$ is the surface modification factor, $S_{\mathrm{u}}$ is the ultimate tensile strength, and value of $a$ and value of $b$ are constants. The value of $K_{\mathrm{S}}$ can be calculated by using the value of $(a$, and $b)$. The value of $a$, and $b$ before machining are given as $515 \mathrm{MPa}$ and 0.3 , respectively. The surface modification factor increased as the increasing of tensile strength or hardness. When the surface roughness Ra improved from $0.32 \mu \mathrm{m}$ to $0.03 \mu \mathrm{m}$, the fatigue limit value increased and the material life also improved. 


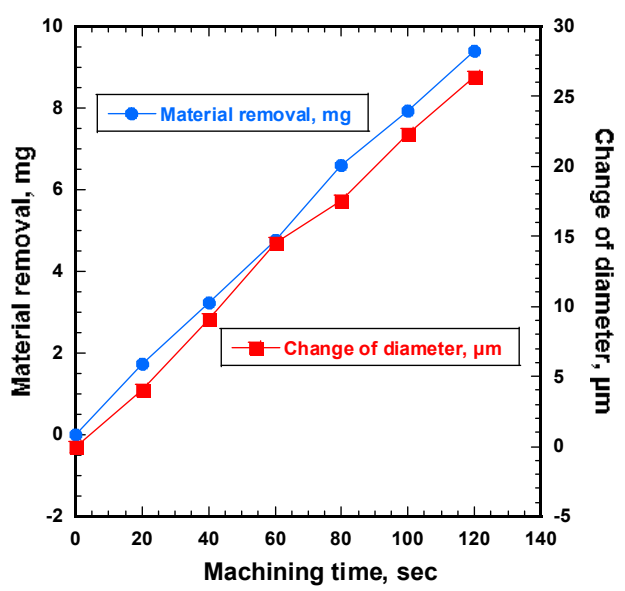

Figure 6. Change of diameter and material removal weight against the machining time at 80,000 rpm $(10 \mathrm{~Hz}, 550 \mathrm{mT}$, and $0.5 \mu \mathrm{m})$.

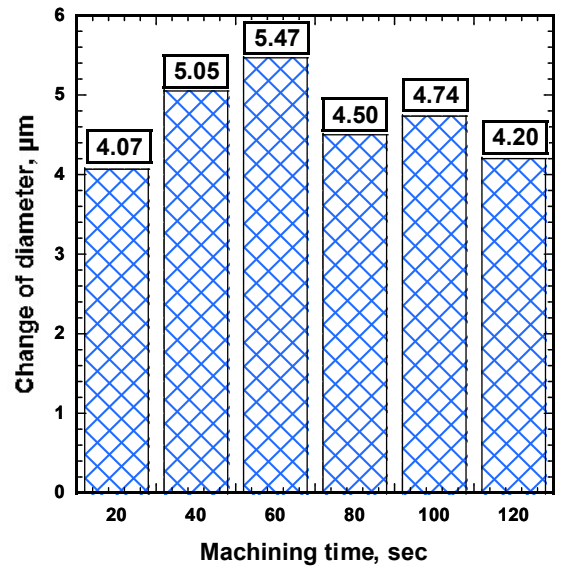

Figure 7. Machining diameter against the machining time at $80,000 \mathrm{rpm}(10 \mathrm{~Hz}, 550 \mathrm{mT}$, and $0.5 \mu \mathrm{m})$.

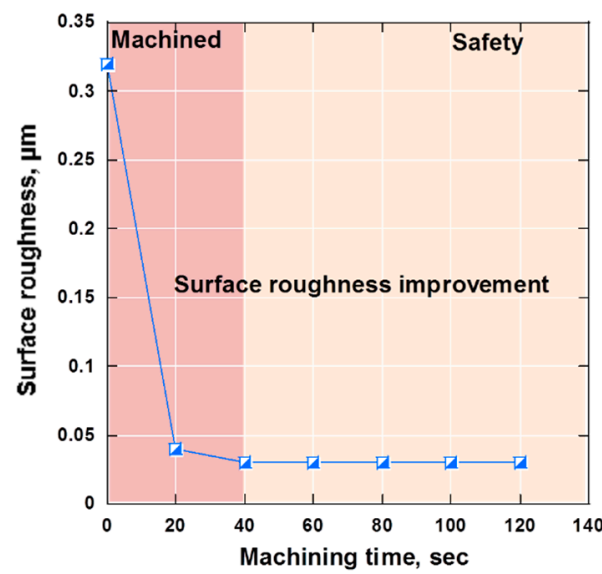

Figure 8. Variations in surface roughness vs. machining time at 80,000 rpm $(10 \mathrm{~Hz}, 550 \mathrm{mT}$, and $0.5 \mu \mathrm{m})$. 


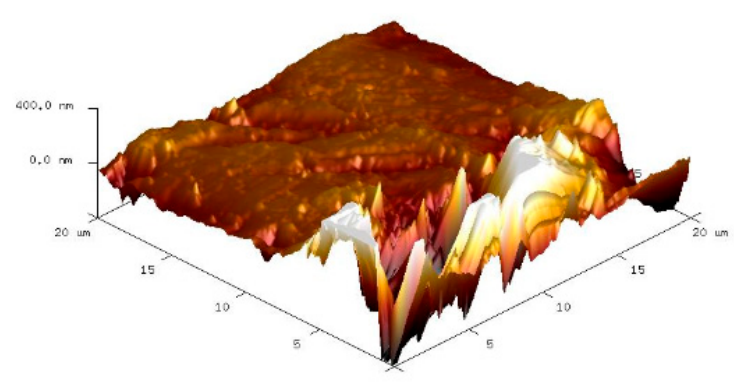

(a)

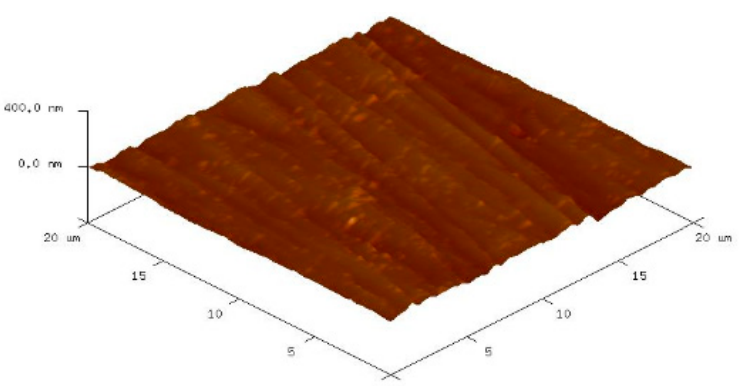

(b)

Figure 9. Atomic Force Microscope (AFM) images of the surfaces before and after being machined by UHSMAM process (a) before machining (Ra: $0.32 \mu \mathrm{m})$ and (b) after machining (Ra: $0.03 \mu \mathrm{m}$, machining time 40-120 s).

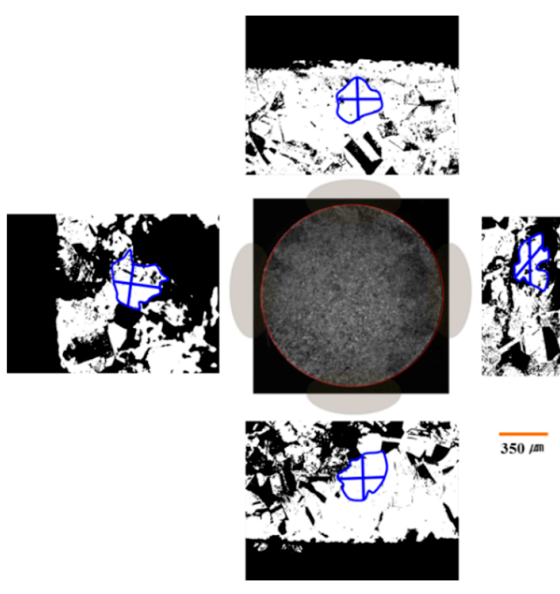

(a)
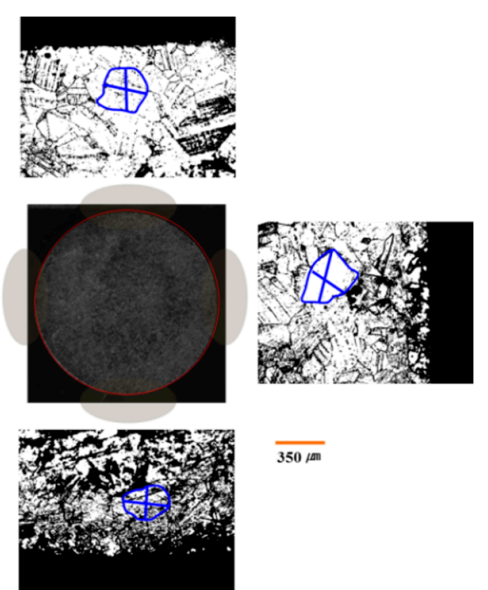

(b)

Figure 10. Recrystallized microstructures showing plastic deformation zone with recrystallization at $950{ }^{\circ} \mathrm{C}$ for $24 \mathrm{~h} \mathrm{(a)} \mathrm{before} \mathrm{ultra-high-speed} \mathrm{machining} \mathrm{and} \mathrm{(b)} \mathrm{after} \mathrm{ultra-high-speed} \mathrm{machining}$ (machining time 40-120 s).

\section{Conclusions}

In this study, the surface accuracy and dimensional accuracy of AISI 304 bars were improved using an ultra-high-speed magnetic abrasive machining process, and then the plastic strain on the machined surface was measured using the subsequent recrystallization technique. The results of this study can be concluded as follows:

1. The study revealed that, an ultra-high-speed magnetic abrasive machining UHSMAM process was successfully performed for achieving high surface accuracy and dimensional accuracy of difficult-to-machine materials such as AISI 304 bars;

2. The best improvements in the precision dimensional accuracy and precision surface accuracy were achieved at $80,000 \mathrm{rpm}$. In terms of the machining micro-diameter, an UHSMAM process can remove $5-\mu \mathrm{m}$ from the diameter of workpiece with every $20 \mathrm{~s}$. In terms of the material removal, the slope showed the constant removal pattern based on the usage of the same grain size of diamond abrasive particle $(0.5 \mu \mathrm{m})$. In terms of the surface roughness, it requires $40 \mathrm{~s}$ to improve the surface roughness from $0.32 \mu \mathrm{m}$ to $0.03 \mu \mathrm{m}$;

3. The subsequent recrystallization technique was applied for measuring the plastic strain on the surface AISI 304 bars after the machining process. Based on the results, it can be confirmed that an UHSMAM process did not cause the impact of plastic deformation. 
4. Based on the results, it can be confirmed that an UHSMAM process is a processing method that can greatly enhance the fatigue limit of the materials and material life.

Author Contributions: Design experiment, methodology, and conceptualization, C.Y. and R.W.; investigation and editing, J.S.K., S.W.L., and S.D.M.; writing paper, C.Y.

Funding: The research was sponsored by National Research Foundation of Korea (NRF) (NRF-2016R1D1A 1B03932103, and NRF-2014R1A1A2059389).

Conflicts of Interest: The authors declare no conflict of interest.

\section{References}

1. Akkurt, A. Surface properties of the cut face obtained by different cutting methods from AISI 304 stainless steel materials. IJEMS 2009, 16, 373-384.

2. Krolczyk, G.M.; Maruda, R.W.; Krolczyk, J.B.; Nieslony, P.; Wojciechowski, S.; Legutko, S. Parametric and nonparametric description of the surface topography in the dry and MQCL cutting conditions. Measurement 2018, 121, 225-239. [CrossRef]

3. Mellal, M.A.; Williams, E.J. Parameter optimization of advanced machining processes using cuckoo optimization algorithm and hoopoe heuristic. J. Intell. Manuf. 2016, 27, 927-942. [CrossRef]

4. Kuhar, M.; Funduk, N. Effects of polishing techniques on the surface roughness of acrylic denture base resins. J. Prosthet. Dent. 2005, 93, 76-85. [CrossRef] [PubMed]

5. Mahajan, D.; Tajane, R. A review on ball burnishing process. Int. J. Sci. Res. Publ. 2013, 3, 1-8.

6. Heng, L.; Yin, C.; Han, S.H.; Song, J.H.; Mun, S.D. Development of a New Ultra-High-Precision Magnetic Abrasive Finishing for Wire Material Using a Rotating Magnetic Field. Materials 2019, 12, 312. [CrossRef] [PubMed]

7. Heng, L.; Kim, Y.J.; Mun, S.D. Review of superfinishing by the magnetic abrasive finishing process. High Speed Mach. 2017, 3, 42-55. [CrossRef]

8. Park, N.J.;Heng, L.D.; Wang, R.; Kim, M.S.; Mun, S.D. Ultra-High-Precision Machining of Microscale-Diameter Zirconia Ceramic Bars by Means of Magnetic Abrasive Finishing. Appl. Mech. Mater. 2016, 851, 98-105. [CrossRef]

9. Singh, D.K.; Jain, V.K.; Raghuram, V. Experimental investigations into forces acting during a magnetic abrasive finishing process. Int. J. Adv. Manuf. Technol. 2006, 30, 652-662. [CrossRef]

10. Bolar, G.; Das, A.; Joshi, S.N. Measurement and analysis of cutting force and product surface quality during end-milling of thin-wall components. Measurement 2018, 121, 190-204. [CrossRef]

11. Wojciechowski, S.; Wiackiewicz, M.; Krolczyk, G.M. Study on metrological relations between instant tool displacements and surface roughness during precise ball end milling. Measurement 2018, 129, 686-694. [CrossRef]

12. Sun, X.; Zou, Y. Study on Electrolytic Magnetic Abrasive Finishing for Finishing Stainless Steel SUS304 Plane with a Special Compound Machining Tool. J. Manuf. Mater. Process. 2018, 2, 41. [CrossRef]

13. Maruda, R.W.; Krolczyk, G.M.; Michalski, M.; Nieslony, P.; Wojciechowski, S. Performance. Structural and microhardness changes after turning of the AISI 1045 steel for minimum quantity cooling lubrication. J. Mater. Eng. Perform. 2017, 26, 431-438. [CrossRef]

14. Iino, Y.; Kim, T.Y.; Mun, S.D. Machined surface plastic strain in orthogonal cutting by subsequent recrystallizations technique. Wear 1996, 199, 211-216. [CrossRef]

15. Yin, C.; Heng, L.; Kim, J.S.; Kim, M.S.; Mun, S.D. Development of a new ecological magnetic abrasive tool for finishing bio-wire material. J. Mech. Sci. Technol. 2019, 12, 714. [CrossRef] [PubMed]

16. McKelvey, S.A.; Fatemi, A. Surface finish effect on fatigue behavior of forged steel. Int. J. Fatigue 2012, 36, 130-145. [CrossRef]

(C) 2019 by the authors. Licensee MDPI, Basel, Switzerland. This article is an open access article distributed under the terms and conditions of the Creative Commons Attribution (CC BY) license (http://creativecommons.org/licenses/by/4.0/). 